\title{
Factors associated with early introduction of complementary feeding and consumption of non-recommended foods among Dutch infants: the BeeBOFT study
}

Lu Wang ${ }^{1}$, Amy van Grieken ${ }^{1}$, Laura A. van der Velde², Eline Vlasblom³, Maaike Beltman³, Monique P. L'Hoir ${ }^{4}$, Magda M. Boere-Boonekamp ${ }^{5}$ and Hein Raat ${ }^{1 *}$ (D)

\begin{abstract}
Background: Timing and types of complementary feeding in infancy affect nutritional status and health later in life. The present study aimed to investigate the factors associated with early introduction of complementary feeding (i.e., before age 4 months), and factors associated with infants consumption of non-recommended foods, including sweet beverages and snack foods.

Methods: This study used cross-sectional data from the BeeBOFT study ( $n=2157)$. Data on complementary feeding practices and potential determinants were obtained by questionnaire at infant's age of 6 months. Logistic regression models were used to investigate factors associated with early introduction of complementary feeding and infants' consumption of non-recommended foods.
\end{abstract}

Results: $21.4 \%$ of infants had received complementary feeding before 4 months of age. At the age of 6 months, 20.2\% of all infants were consuming sweet beverages daily and $16.5 \%$ were consuming snack foods daily. Younger maternal age, lower maternal educational level, absence or shorter duration of breastfeeding, parental conviction that "my child always wants to eat when he/she sees someone eating" and not attending day-care were independently associated with both early introduction of complementary feeding and the consumption of non-recommended foods. Higher maternal pre-pregnancy BMI and infant postnatal weight gain were associated only with early introduction of complementary feeding.

Conclusions: We identified several demographical, biological, behavioral, psychosocial, and social factors associated with inappropriate complementary feeding practices. These findings are relevant for designing intervention programs aimed at educating parents.

Trial registration: The trail is registered at Netherlands Trial Register, trail registration number: NTR1831. Retrospectively registered on May 29, 2009.

Keywords: Introduction of complementary feeding, Sweet beverage, Snack foods, Risk factors

\footnotetext{
*Correspondence: h.raat@erasmusmc.nl

${ }^{1}$ Department of Public Health, Erasmus University Medical Center, PO Box

2040, 3000 CA, Rotterdam, the Netherlands

Full list of author information is available at the end of the article
}

(c) The Author(s). 2019 Open Access This article is distributed under the terms of the Creative Commons Attribution 4.0 International License (http://creativecommons.org/licenses/by/4.0/), which permits unrestricted use, distribution, and reproduction in any medium, provided you give appropriate credit to the original author(s) and the source, provide a link to the Creative Commons license, and indicate if changes were made. The Creative Commons Public Domain Dedication waiver (http://creativecommons.org/publicdomain/zero/1.0/) applies to the data made available in this article, unless otherwise stated. 


\section{Background}

Complementary feeding for infants is defined as feeding solid foods and liquids other than breast milk or infant formula [1, 2]. Since 2001, the WHO has recommended that complementary feeding be introduced after the age of 6 months [2]. The European Society for Pediatric Gastroenterology, Hepatology and Nutrition (ESPGHAN) recommends introducing complementary feeding not before 17 weeks and no later than 26 weeks $[1,3]$. In the Netherlands, Jeugdgezondheidszorg (preventive Youth Health Care) is a government-funded program for monitoring children's health and development, and providing health promotion and disease prevention at set ages; the care is offered for free [4]. Approximately 95\% of children in the Netherlands participate in this preventive Youth Health Care (henceforth YHC) program [4]. In line with ESPGHAN guidelines, the YHC guideline suggests introducing complementary feeding after the age of 4 months [5].

Despite the inconsistencies in the current guidelines regarding when to introduce complementary feeding, all guidelines agree that complementary feeding should not be introduced before the age of 4 months $[1,3,5]$. Although introducing complementary feeding earlier may contribute to more rapid weight gain during infancy [68] and increased risk of childhood obesity in affluent populations [9-12], the introduction of complementary feeding before 4 months is common in many countries. For instance, the percentage of infants introduced to complementary feeding before the age of 4 months was 37\% in a birth cohort born in 2007 and 2008 in Northwest Italy [13], 30\% across the UK in 2010 [14], and 40\% among infants born between 2005 and 2007 participating in a national study in the US [15]. To the best of our knowledge, no study has reported the prevalence of introducing complementary feeding before 4 months in the Netherlands.

It is not only the timing of the introduction of complementary feeding that is important but also the type of food introduced. Current guidelines recommend avoiding foods high in fat, salt or sugar and low in nutritional value in the first year of life $[3,5,16]$. A high intake of foods such as sweet desserts [17] and sweet beverages [18] during infancy is associated with a high intake of these food types in later life, and with childhood overweight and obesity [17]. Furthermore, excessive intake of sugar-sweetened beverages during infancy may result in diarrhea [19], failure to thrive [20], tooth decay [21], and decline in the consumption of other nutritious foods. It has been shown that a substantial proportion of infants consume sweet beverages and snack foods such as chocolate, cookies, and chips [22-25].

To develop targeted interventions to discourage the early introduction of complementary feeding and the consumption of non-recommended food types among infants, it is important to identify the determinants of both practices. Previous studies have identified a range of maternal and infant related factors associated with early introduction of complementary feeding, such as maternal age, maternal educational level, and maternal Body Mass Index (BMI), infant size or postnatal weight gain, and the initiation and duration of breastfeeding [26-33]. Psychosocial factors have so far received scant research attention: one study has suggested that mothers may introduce complementary feeding earlier in response to the infant's fussy temperament [34], another has shown the influence of certain parental beliefs about infant feeding and infant weight status [35]. Factors associated with infants' consumption of non-recommended foods (i.e., energy-dense, nutrient-poor foods and sweet beverages) have also received little attention [24, 25]. Furthermore, the single study we found performed in the Netherlands on factors associated with the timing of complementary feeding introduction [29] did not assess factors associated with the introduction of complementary feeding before child age 4 months [29].

As complementary feeding practices have been found to differ between countries [36], in order to develop population-specific strategies it is important to explore factors associated with complementary feeding practices in different settings. Our study therefore aimed to investigate factors associated with inappropriate complementary feeding practices, including the early introduction of complementary feeding, and the consumption of non-recommended foods, including sweet beverages and snack foods, in a population-based sample of parents and children in the Netherlands. We considered a range of demographic, biological, behavioral, psychosocial, and social factors, and explored their associations with inappropriate complementary feeding practices.

\section{Methods \\ Study design and study population}

We performed secondary data analysis using data from the BeeBOFT study, which is a population-based cluster randomized controlled trial for the primary prevention of overweight among young children ( $0-3$ years) in the Netherlands [37]. In total, 51 YHC teams covering urban and rural areas in the Netherlands participated. Each YHC organization serves a region of the Netherlands, and each YHC team within an organization serves one or more municipalities of the region [4]. A team comprises a physician, nurse, and assistant [4]. The 51 YHC teams were randomly allocated to three study arms, the "BBOFT+" intervention (17 teams), the "E-health4Uth" intervention (17 teams), or the control group (17 teams). At each routine $\mathrm{YHC}$ visit (scheduled at child ages of $0.5,1,2,3,4,6,9,11,14,18$, and 36 months), parents 
allocated to the "BBOFT+" group received an intervention on child-rearing skills concerning healthy behavioral lifestyle habits of the child from birth onward. Parents allocated to the "E-health4Uth" group received intervention twice: at child ages of circa 18 and 24 months. Parents in the control group received usual care. After reviewing the research proposal of the BeeBOFT study, the Erasmus University Medical Center Medical Ethics Committee concluded that the Dutch Medical Research Involving Human Subjects Act did not apply to it. The Medical Ethics Committee therefore had no objection to the execution of the BeeBOFT study (proposal number MEC-2008-250).

From January 2009 through September 2010, parents were invited to participate in the BeeBOFT study when one of the 51 participating YHC teams visited them at home 2-4 weeks after the birth of the child. In total, 3003 parents provided written informed consent and filled in the baseline questionnaire. At child age 6 months, all the parents were invited to complete a questionnaire regarding their child's health-related behaviors, including timing of introduction of complementary feeding, the frequency of consumption of complementary feeding, and the determinants of these behaviors. A total of 2331 parents returned the questionnaire at child age 6 months (age range 6-8 months). The questionnaire asked about the timing of the introduction of 22 types of food. Children for whom values were missing for more than five food types were excluded $(n=48)$. We also excluded preterm babies (gestational age $<37$ weeks, $n=126$ ). Finally, 2157 parent-child dyads were included in the present study.

Compared with the 672 infants excluded due to non-response for the questionnaire, the infants whose parents have responded the questionnaire $(n=2331)$ at child age 6 months had higher educated (20.0\% low educated VS $11.4 \%$ low educated, $p<0.01$ ).

\section{Measurements \\ Infant complementary feeding}

Timing of complementary feeding At child age 6 months, parents were asked to report in the questionnaire at which age the child had received the following products (Additional file 1: Table S1): fruit juice; fruit juice concentrate; soft drinks (e.g., cola, iced tea); light soft drinks; fruit cordials or syrup; sweetened dairy drinks; milk or buttermilk; yogurt; porridge; bread; baby cookies; chocolate or candy; crackers or breadsticks; fruit from a jar; fresh fruit; vegetables from a jar; vegetables with fish or meat from a jar; pasta/rice/potato; fresh vegetable; fish/meat/meat substitutes. The response categories included: "< 1 month", "between 1-2 months", "between 2-3 months", "between 3-4 months", "between 4-5 months", "older than 5 months", and "never given". Parents could choose "never given" if at the time they filled in the questionnaire they had not introduced that food item. For descriptive analysis, the response categories "< 1 month", "between 1-2 months", "between 23 months", and "between 3-4 months" were combined into "before 4 months". The average age of the infants when parents filled in the questionnaire was 6.3 months, $\mathrm{SD}=0.6$. The drinks fruit juice, fruit juice concentrate, soft drinks, fruit cordial or syrup, and sweetened dairy drinks were combined into one category called sweet beverages. The foods baby cookies and chocolate or candy were combined into one category called snack foods. The timing of introduction of complementary feeding was defined as the earliest time point that any of the abovementioned drinks and foods were first given to the child. Early introduction of complementary feeding was defined as introduction of complementary feeding (i.e., drinks and foods) before 4 months.

Frequent consumption of non-recommended foods The questionnaire also assessed how frequently on average the child was given the abovementioned food products when parents filled in the questionnaire at 6 months (Additional file 1: Table S1). The response categories included: "never given", "<once per week", "1-3 times per week", "4-6 times per week", "1-2 times per day", "3-4 times per day", and " $>5$ times per day". The non-recommended foods included sweet beverages and snack foods as defined above. Frequent consumption of non-recommended foods was defined as the consumption of sweet beverages and/or snack foods $\geq 1$ time per day.

\section{Independent variables}

Based on previous research [26-32, 38], the following variables were selected as potential determinants for the early introduction of complementary feeding and consumption of non-recommended foods.

Demographic characteristics The demographic characteristics obtained by the baseline questionnaire were maternal age (years), maternal educational level, maternal ethnic background (native/non-native), maternal employment status (employed/unemployed), family structure (single parent/two parents), child gender (girl/boy), parity (primipara/multipara), and gestational age (weeks). Maternal educational level was categorized as high (higher vocational training, university degree), middle ( $>4$ years general secondary school or intermediate vocational training), and low (no education, primary school, or 4 years or less general secondary school) [39]. The mother's ethnic background was classified as non-native if one of her parents had been born outside the Netherlands [40]. 
Biological factors Maternal pre-pregnancy weight and height were self-reported in the baseline questionnaire. Maternal pre-pregnancy BMI was calculated by weight $(\mathrm{kg}) /$ height $^{2}$ (meters). Data on child weight at birth and at age 3 months were acquired from the YHC registration files. Child weight and height were measured by YHC professionals in accordance with standardized protocols at each routine visit (set at ages 0, 1, 2, 3, 4, 6 months) [41]. Child weight for age Z-score 7 was calculated using the Dutch 1997 age- and gender- specific reference values [42]. Infant postnatal weight gain between age $0-3$ months was calculated by subtracting the weight for age Z-score at birth from the weight for age Z-score at 3 months.

Behavioral factors At child age 6 months, parents were asked to report whether they had started breastfeeding (yes, no), and, if so, how old the child was when the mother stopped breastfeeding (response categories included within 2 weeks, between 2 and 4 weeks, between 1 and 2 months, between 2 and 3 months, between 3 and 4 months, between 4 and 5 months, older than 5 months, and still breastfeeding) (Additional file 1: Table S1). The responses to these two questions led us to create a new variable indicating the duration of any breastfeeding: "no breastfeeding", "breastfeeding for 0.5-4 months", or "breastfeeding for 4 months or longer".

Psychosocial factors The psychosocial factors maternal depressive symptoms, parental beliefs, and infant temperament were assessed by parental questionnaire at child age 6 months. Maternal depressive symptoms were assessed using the 10-question Edinburgh Postnatal Depression Scale [43]. Mothers scoring 10 or higher were classified as having depressive symptoms. This variable was defined as missing if the questionnaire had been filled in by the father or another care giver $(n=107)$.

Parental beliefs/perceptions about infant characteristics, feeding, and infant weight were assessed. The items are based on a previous study investigating parental views on child overweight-related behaviors [44]. Example items included the following statements "My child always wants to eat when he/she sees someone eating", "Fruit and vegetables can be given to the baby freely earlier than 4 months" and "I don't like my child to be fat". Parents could respond on a 5-point scale ranging from "strongly agree" to "strongly disagree". The responses were dichotomized into " 1 " indicating agree/strongly agree, and " 0 " indicating neutral, disagree, or strongly disagree.

Infant temperament, e.g., soothability, distress to limitations, and distress to novel food, was measured using subscales from the Infant Behavior Questionnaire [45]. The subscales were chosen based on previous research on infant temperament and infant feeding [34]. An example item used to measure soothability was "When part of the child's body was patted or stroked, how often did she/he calm down immediately?", for distress to limitations, "When having to wait for food or liquids during the last week, how often did the child cry loudly", and for distress to novel food, "When given a new food or liquid, how often did the child accept it immediately?". Parents rated these specific child behaviors on a 7-point scale ranging from 1 ("Never") to 7 ("always").

Social factors Day-care attendance of the infants was reported by parents in the questionnaire at child age 6 months. In addition, we included a variable entitled "intervention group" for the current study. Parents allocated to the "BBOFT+" study arm were defined as the "BBOFT+ intervention" group, while parents allocated to the control group or the "E-health" intervention group were combined to form a "no intervention" group.

\section{Statistical analysis}

All statistical analyses were performed using SAS version 9.4. Descriptive statistics for the study population were presented in relation to the timing of the introduction of complementary feeding ( $<4$ months vs $\geq 4$ months). Differences between the two groups were compared by independent sample $t$ test for continuous variables, and by the $x^{2}$ test for categorical variables.

Intra-class coefficients (ICC) for our outcome variables (early introduction of complementary feeding and consumption of non-recommended foods) were calculated to decide whether the outcome variables differed for the participating YHC teams. The ICCs for both outcome variables were 0.02 , suggesting a very low intra-class correlation and therefore multilevel modeling was not used. In addition, we found no significant influence of the intervention group on both outcome variables (both $p>$ 0.25 ). We therefore applied normal logistic regression analyses to the data on all available participants to assess the factors associated with the early introduction of complementary feeding and with the frequent consumption of non-recommended foods. First, univariate logistic regression models were fitted for each of the independent variables with the outcome variables. Second, independent variables that were significantly $(p<0.05)$ associated with the outcome variables in the univariate models were included in the multivariate model, to assess the independent association between the factors and outcome variables. The univariate and multivariate models were both adjusted for the exact age of the child.

\section{Results}

Sample characteristics

Table 1, which presents the characteristics of the mothers and infants in relation to the timing of the 
Table 1 Characteristics of the total study population $(n=2157)$

\begin{tabular}{|c|c|c|c|c|}
\hline \multirow[t]{2}{*}{ Variable } & \multirow[t]{2}{*}{ Missing (N) } & \multicolumn{2}{|c|}{ Age at introduction of complementary feeding } & \multirow[t]{2}{*}{$p$ value } \\
\hline & & $\begin{array}{l}>4 \text { months } \\
N(\%)\end{array}$ & $\begin{array}{l}<4 \text { months } \\
\mathrm{N}(\%)\end{array}$ & \\
\hline Total & & $1695(78.58)$ & $462(21.42)$ & \\
\hline \multicolumn{5}{|l|}{ Demographic characteristics } \\
\hline Maternal age at child birth, years, mean (SD) & 31 & $31.36(4.1)$ & $29.7(4.3)$ & $<0.001$ \\
\hline Maternal educational level & 13 & & & $<0.001$ \\
\hline Low & & $147(8.7)$ & $96(21.1)$ & \\
\hline Middle & & $576(34.1)$ & 195(42.8) & \\
\hline High & & $967(57.2)$ & 165(36.2) & \\
\hline Maternal ethnic background, native & 4 & 1533(90.3) & $407(88.1)$ & 0.15 \\
\hline Maternal employment status, employed & 4 & 1449(85.6) & $377(81.6)$ & 0.04 \\
\hline Family structure, single parent & 23 & 1659(98.7) & $440(96.7)$ & $<0.01$ \\
\hline Infant gender, boy & 1 & $843(49.7)$ & $263(57.1)$ & $<0.01$ \\
\hline Parity, primipara & 0 & $747(44.0)$ & 251(54.3) & $<0.001$ \\
\hline \multicolumn{5}{|l|}{ Biological factors } \\
\hline Maternal pre-pregnancy BMI & 5 & $24.0(4.3)$ & $25.0(4.9)$ & 0.02 \\
\hline Infant gestational age at birth, weeks, mean (SD) & 0 & $39.8(1.0)$ & $39.7(1.0)$ & 0.10 \\
\hline Infant weight at birth, Z-score, mean (SD) & 10 & $0.4(1.0)$ & $0.3(1.0)$ & 0.03 \\
\hline Infant postnatal weight gain, Z-score, mean (SD) & 677 & $-0.7(0.8)$ & $-0.5(0.9)$ & $<0.001$ \\
\hline \multicolumn{5}{|l|}{ Behavioral factors } \\
\hline Duration of any breastfeeding & 6 & & & $<0.001$ \\
\hline No breastfeeding & & $360(21.3)$ & 169(36.8) & \\
\hline Breastfeeding for $0.5-4$ months & & $547(19.4)$ & 207(26.8) & \\
\hline Breastfeeding for 4 months or longer & & 789(46.6) & $83(18.1)$ & \\
\hline \multicolumn{5}{|l|}{ Psychosocial factors } \\
\hline Maternal depressive symptom, yes ${ }^{a}$ & 119 & 1445(89.7) & $371(86.5)$ & 0.054 \\
\hline \multicolumn{5}{|l|}{ Parental perceptions on infant characteristics, (agree/strongly agree) } \\
\hline "My baby drinks greedily" & 23 & $477(28.4)$ & 135(29.6) & 0.07 \\
\hline "My child always wants to eat when he/she sees someone eating" & 23 & $559(33.3)$ & 212(46.6) & $<0.001$ \\
\hline "My child does not like plain water" & 45 & 293(17.6) & $114(25.2)$ & $<0.001$ \\
\hline "My child cried a lot in the first 3 months" & 16 & $300(17.8)$ & 99(21.6) & 0.06 \\
\hline \multicolumn{5}{|l|}{ Parental beliefs about feeding, (agree/strongly agree) } \\
\hline "Fruit and vegetables can be given to the baby freely earlier than 4 months" & 20 & $39(2.3)$ & 70(15.4) & $<0.001$ \\
\hline \multicolumn{5}{|l|}{ Parental beliefs about infant weight, (agree/strongly agree) } \\
\hline "I don't like my child to be fat" & 20 & $1206(71.7)$ & 296(64.9) & $<0.01$ \\
\hline "I don't like my child to be thin" & 15 & $924(54.8)$ & 234(51.1) & 0.18 \\
\hline \multicolumn{5}{|l|}{ Infant temperament } \\
\hline Soothability, mean (SD) & 31 & $4.8(1.2)$ & $4.7(1.3)$ & 0.06 \\
\hline Distress to limitation, mean (SD) & 33 & $2.8(0.9)$ & $2.7(0.9)$ & 0.27 \\
\hline Distress to novel food, mean (SD) & 36 & $2.3(1.4)$ & $2.2(1.3)$ & 0.02 \\
\hline \multicolumn{5}{|l|}{ Social care factors } \\
\hline Day-care attendance, yes & 25 & $1250(74.4)$ & $297(65.4)$ & $<0.001$ \\
\hline "BBOFT+" intervention ${ }^{\mathrm{b}}$ & 0 & $509(30.0)$ & $127(27.5)$ & 0.27 \\
\hline
\end{tabular}

${ }^{a}$ Maternal depressive symptom was defined as a score of 10 or greater on the Edinburgh Postnatal Depression Scale. This variable was defined as missing if the questionnaire had been filled in by the father or other care givers $(n=107)$

'The "BBOFT+ Intervention" group comprised the group of parents allocated to the BBOFT+ study arm; "no intervention" comprised the groups of parents allocated to the control group or to the "E-health" intervention group 
introduction of complementary feeding, shows that $11.3 \%$ of mothers were low educated, $36.0 \%$ were middle educated, and $52.7 \%$ high educated, and that $24.6 \%$ had not breastfed, whereas $40.6 \%$ of the mothers had breastfed but stopped doing so before the child was 4 months.

\section{Complementary feeding practices}

Table 2 presents the timing of the introduction of different types of complementary food. Overall, the percentage of infants who had been given any type of complementary food at the age of 3,4 , and 5 months was $4.5 \%$ (data not shown in table), 21.4 , and $38.1 \%$ respectively. At the moment parents filled in the questionnaire (mean age $=6.4$ months, SD $=0.7$ ), $98.7 \%$ of the infants had been given some type of complementary food. The food products most frequently introduced before 4 months were porridge $(11.8 \%)$, fruit (11.0\%), vegetables $(6.4 \%)$, and sweet beverages $(6.1 \%)$.

Figure 1 presents the frequency of consumption of sweet beverages and snack foods by the infants. At the age of 6 months, $41 \%$ of the infants were consuming sweet beverages at least once a week and $20.2 \%$ of the infants were consuming sweet beverages daily. In addition, $35 \%$ of the infants were consuming snack food at least once weekly, and $16.5 \%$ of the infants were consuming snack food daily. In total, $27.0 \%$ of the infants were consuming non-recommended foods (i.e., sweet beverages and/or snack food) at least once daily.

\section{Factors associated with early introduction of complementary feeding}

Table 3 shows the results of univariate and multivariate logistic regression models for factors associated with early introduction of complementary feeding (i.e., introduction of complementary feeding before child age 4 months). The demographic characteristics independently associated with early introduction of complementary feeding were younger maternal age and lower maternal educational level. For biological factors: increased maternal pre-pregnancy BMI and increased infant postnatal weight gain were independently associated with higher odds of early introduction of complementary feeding. For behavioral factors: compared to any breastfeeding for 4 months or longer, no breastfeeding or breastfeeding for less than 4 months was independently associated with early introduction of complementary feeding. For psychosocial factors: the beliefs "fruit and vegetables can be given to the baby freely earlier than 4 months", and "my child always wants to eat when he/she sees someone eating" were independently associated with higher odds of early introduction of complementary feeding. For social factors, day-care attendance was independently associated with lower odds of early introduction of complementary feeding.

\section{Factors associated with frequent consumption of non- recommended foods}

The results of the multivariate logistic regression model (Table 4) suggest that younger maternal age, lower maternal educational level, and no breastfeeding or breastfeeding for less than 4 months were associated with frequent consumption of non-recommended foods (once or more per day) of the infants at the age of 6 months. Of the psychosocial factors, the beliefs "fruit and vegetables can be given to the child freely earlier than 4

Table 2 The timing of introduction of different types of complementary food $(N=2157)$

\begin{tabular}{|c|c|c|c|c|}
\hline \multirow{2}{*}{$\begin{array}{l}\text { Type of complementary } \\
\text { food }\end{array}$} & \multirow{2}{*}{$\begin{array}{l}\text { Before } 4 \text { months } \\
N(\%)\end{array}$} & \multirow{2}{*}{$\begin{array}{l}\text { Between 4-5 months } \\
N(\%)\end{array}$} & \multirow{2}{*}{$\begin{array}{l}\text { After age } 5 \text { months }^{a} \\
N(\%)\end{array}$} & \multirow{2}{*}{$\begin{array}{l}\text { Never given }{ }^{\mathrm{b}} \\
\mathrm{N}(\%)\end{array}$} \\
\hline & & & & \\
\hline Sweet beverages $^{c}$ & $132(6.1)$ & $251(11.6)$ & $740(34.3)$ & $1036(48.0)$ \\
\hline Milk or buttermilk & $18(0.8)$ & $8(0.4)$ & $57(2.7)$ & 2067(96.1) \\
\hline Yogurt & $32(1.5)$ & $99(4.6)$ & $611(28.4)$ & 1413(65.6) \\
\hline Porridge & 255(11.8) & $605(28.0)$ & $719(33.3)$ & $580(26.9)$ \\
\hline Bread & $10(0.5)$ & $81(3.8)$ & 1019(47.2) & $1047(48.5)$ \\
\hline Snack foods ${ }^{d}$ & $16(0.7)$ & $124(5.7)$ & 713(33.0) & $1306(60.5)$ \\
\hline Crackers or breadsticks & $4(0.2)$ & $55(2.6)$ & $484(22.5)$ & $1610(74.8)$ \\
\hline Fruit & $236(11.0)$ & $791(36.7)$ & $1067(49.5)$ & $62(2.9)$ \\
\hline Vegetables & $137(6.4)$ & 638(29.6) & $1240(57.4)$ & $144(6.7)$ \\
\hline Pasta/potato/rice & $16(0.7)$ & $112(5.2)$ & 1072(49.8) & $952(44.2)$ \\
\hline Fish/meat/meat substitutes & $34(1.6)$ & 163(7.6) & $1120(51.9)$ & $841(39.0)$ \\
\hline Any complementary food & $462(21.4)$ & $875(40.5)$ & $794(36.8)$ & $28(1.3)$ \\
\hline
\end{tabular}

${ }^{a}$ After the child reached the age of 5 months, and before the time parent completed the questionnaire on infant feeding. The mean age of the infants at questionnaire completion was 6.3 months $(S D=0.6)$

${ }^{\mathrm{b}}$ Complementary feeding had not yet been introduced to the infant when parents filled in the questionnaire

Including fruit juice, fruit juice concentrate, soft drinks (e.g. cola, iced tea), fruit cordials or syrup, and sweetened dairy products

dincluding baby cookies, and chocolate or candy 


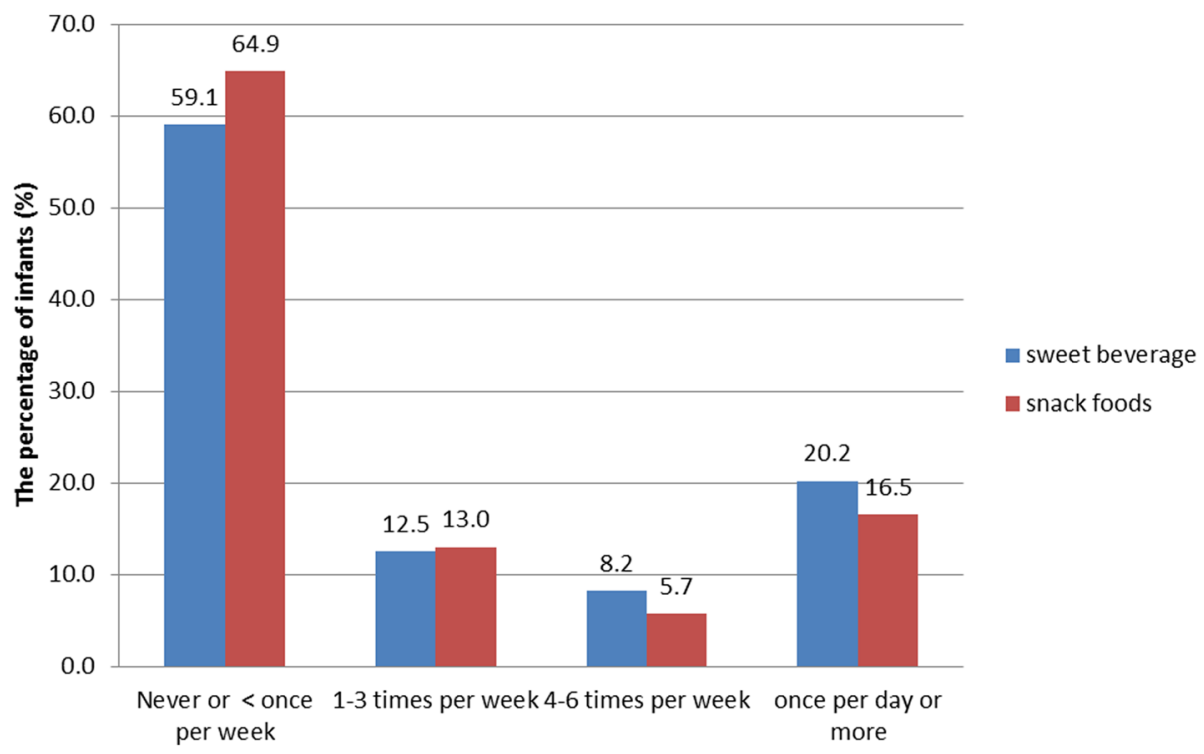

Fig. 1 The frequency of consumption of non-recommended foods by the infant at the age of 6 months $(n=2157)$

months" and "my child always wants to eat when he/she sees someone eating" were associated with frequent consumption of non-recommended foods. Infant temperament "soothability" was positively associated with frequent consumption of non-recommended foods, while "distress to novel food" was negatively associated with frequent consumption of non-recommended foods. Of the social factors, day-care attendance was associated with lower consumption of non-recommended foods.

\section{Discussion}

In our population-based sample of parent-child dyads from the Netherlands, $21 \%$ of the infants were introduced to complementary feeding before the age of 4 months, and $38 \%$ of the infants were introduced to complementary feeding after 5 months. Less than $2 \%$ of the infants had not received any complementary feeding at the moment of questionnaire completion (mean age of the infants then was 6.3 months). In addition, we observed that a significant proportion of the infants were consuming sweet beverages or snack food at age 6 months, pointing to a need to put greater emphasis on discouraging giving sweet beverages and snack foods to infants.

In line with previous research $[25,26,33,46]$, we found that mothers who were younger, less educated, and who did not initiate breastfeeding or breastfed for shorter duration were more likely to introduce complementary feeding early. In addition, our results suggest that these factors are also associated with frequent consumption of non-recommended foods among the infants. Our findings underline the need to develop effective interventions targeting these groups of mothers (i.e., younger, lower educated, and not breastfeeding) to improve their feeding practices, including the timing and types of complementary feeding.

Our results suggest that mothers with higher pre-pregnancy BMI were more likely to introduce complementary feeding early. Previous studies have suggested that maternal pre-pregnancy overweight/obesity is linked to impaired lactogenesis [47-49]. Overweight or obese mothers may have difficulty initiating or sustaining breastfeeding, and therefore may introduce complementary feeding earlier to compensate for the insufficiencies in breastmilk. In line with this hypothesis, we found that the association between maternal pre-pregnancy BMI and early introduction of complementary feeding was reduced to borderline significance after adjusting for breastfeeding duration (data not shown).

Our results reveal that infants with more rapid postnatal weight gain were more likely to receive complementary feeding early. This finding is consistent with previous evidence $[6,50,51]$. Our study further confirmed that rapid postnatal weight gain was associated with early introduction of complementary feeding independent of factors such as breastfeeding duration. A possible explanation for this association is that infants who grow faster in the first few months may show more hunger cues, or signs of readiness for complementary feeding. Rapid weight gain in the first few months is associated with increased risk of overweight [52-54], and cardiovascular risk factors in later life [55-57]. Early introduction of complementary feeding may further increase infants' energy intake and growth velocity [6-8]. Future research investigating the influence of 
Table 3 Factors associated with early introduction of complementary feeding

\begin{tabular}{|c|c|c|}
\hline & \multicolumn{2}{|c|}{$\begin{array}{l}\text { Early introduction of complementary feeding } \\
<4 \text { months vs }>4 \text { months }\end{array}$} \\
\hline & Univariate models & Multivariate model \\
\hline & OR $(95 \% \mathrm{Cl})$ & OR $(95 \% \mathrm{Cl})$ \\
\hline \multicolumn{3}{|l|}{ Demographic characteristics } \\
\hline Maternal age at child birth (years) & $0.91(0.88,0.93)^{* * *}$ & $0.94(0.91,0.98)^{* *}$ \\
\hline \multicolumn{3}{|l|}{ Maternal educational level } \\
\hline Low vs high & $3.82(2.82,5.19)^{* * *}$ & $2.48(1.57,3.92)^{* * *}$ \\
\hline Middle vs high & $1.98(1.57,2.50)$ & $1.26(0.91,1.75)$ \\
\hline Maternal ethnic background, non-native vs native & $1.23(0.88,1.71)$ & \\
\hline Maternal employment status, unemployed vs employed & $1.33(1.02,1.75)^{*}$ & $0.90(0.57,1.39)$ \\
\hline Family structure, single parent vs two parents & $2.56(1.32,4.97)^{* *}$ & $1.88(0.69,5.13)$ \\
\hline Infant gender, girl vs boy & $0.74(0.60,0.92)^{* *}$ & $0.90(0.67,1.20)$ \\
\hline Parity, multipara vs primipara & $0.66(0.54,0.81)^{* * *}$ & $0.79(0.58,1.08)$ \\
\hline \multicolumn{3}{|l|}{ Biological factors } \\
\hline Maternal pre-pregnancy BMI & $1.05(1.02,1.07)^{* * *}$ & $1.02(1.00,1.06)$ \\
\hline Infant gestational age (weeks) & $0.92(0.83,1.02)$ & \\
\hline Infant weight at birth, Z-score & $0.82(0.66,1.01)$ & \\
\hline Infant postnatal weight gain, Z-score ${ }^{a}$ & $1.33(1.15,1.55)^{* * *}$ & $1.24(1.05,1.50)^{*}$ \\
\hline \multicolumn{3}{|l|}{ Behavioral factor } \\
\hline \multicolumn{3}{|l|}{ Duration of any breastfeeding } \\
\hline No breastfeeding & $4.47(3.34,5.97)^{* * *}$ & $2.84(1.90,4.30)^{*}$ \\
\hline Breastfeeding for $0.5-4$ months & $3.62(2.75,4.78)^{* *}$ & $2.63(1.82,3.80)^{*}$ \\
\hline Breastfeeding for 4 months or longer & Ref & Ref \\
\hline \multicolumn{3}{|l|}{ Psychosocial factors } \\
\hline Maternal depressive symptoms, yes vs no ${ }^{b}$ & $1.35(0.98,1.86)$ & \\
\hline \multicolumn{3}{|l|}{ Parental perceptions on infant characteristics ${ }^{c}$} \\
\hline "My child drinks greedily" & $1.06(0.85,1.34)$ & \\
\hline "My child always wants to eat when he/she sees someone eating" & $1.75(1.42,2.16)^{* * *}$ & $1.50(1.11,2.01)^{* *}$ \\
\hline "My child does not like plain water" & $1.58(1.23,2.02)^{* * *}$ & $1.08(0.76,1.54)$ \\
\hline "My child cried a lot in the first 3 months" & $1.28(0.99,1.65)$ & \\
\hline \multicolumn{3}{|l|}{ Parental belief about feeding ${ }^{c}$} \\
\hline "Fruit and vegetables can be given to the baby freely earlier than 4 months" & $7.61(5.07,11.44)^{* * *}$ & $5.60(3.18,9.85)^{* * *}$ \\
\hline \multicolumn{3}{|l|}{ Parental beliefs about infant weight ${ }^{c}$} \\
\hline "I don't like my child to be fat" & $0.73(0.59,0.91)^{* *}$ & $0.82(0.59,1.11)$ \\
\hline "I don't like my child to be thin" & $0.86(0.70,1.06)$ & \\
\hline \multicolumn{3}{|l|}{ Infant temperament } \\
\hline Soothability & $0.93(0.86,1.01)$ & \\
\hline Distress to limitations & $0.94(0.83,1.05)$ & \\
\hline Distress to novel food & $0.91(0.84,0.98)$ & $0.90(0.80,1.01)$ \\
\hline \multicolumn{3}{|l|}{ Social care factors } \\
\hline Day-care attendance, yes vs no & $0.65(0.52,0.81)^{* *}$ & $0.66(0.47,0.93)^{*}$ \\
\hline "BBOFT+" intervention vs no intervention & $0.89(0.70,1.11)$ & \\
\hline
\end{tabular}

Note: The multivariate model included the factors significantly $(p<0.05)$ associated with the outcome variable in the univariate models ${ }^{*} p<0.05,{ }^{* *} p<0.01,{ }^{* * *} p<0.001, p<0.10$

${ }^{a}$ Calculated by changes in weight for age Z-scores in the first 3 months

${ }^{\mathrm{b}}$ Maternal depressive symptom was defined as scored 10 or greater on the Edinburgh Postnatal Depression Scale. This variable was defined as

missing if the questionnaire had been filled in by the father or other care givers $(n=107)$

${ }^{c}$ Agree/strongly agree vs neutral, disagree, or strongly disagree 
Table 4 Factors associated with the consumption of non-recommended foods

\begin{tabular}{|c|c|c|}
\hline & \multicolumn{2}{|c|}{$\begin{array}{l}\text { Frequent consumption of non-recommended foods } \\
\geq \text { once per day vs }<\text { once per day }\end{array}$} \\
\hline & Univariate models & Multivariate model \\
\hline & OR $(95 \% \mathrm{Cl})$ & OR $(95 \% \mathrm{Cl})$ \\
\hline \multicolumn{3}{|l|}{ Demographic characteristics } \\
\hline Maternal age at child birth (years) & $0.93(0.91,0.96)^{* * *}$ & $0.96(0.94,0.99)^{*}$ \\
\hline \multicolumn{3}{|l|}{ Maternal educational level } \\
\hline Low vs high & $2.90(2.15,3.92)^{* * *}$ & $2.02(1.42,2.86)^{* * * *}$ \\
\hline Middle vs high & $1.73(1.40,2.15)^{*}$ & $1.36(1.07,1.73)^{*}$ \\
\hline Maternal ethnic background, non-native vs native & $1.28(0.94,1.75)$ & \\
\hline Maternal employment status, unemployed vs employed & $1.23(0.95,1.60)$ & \\
\hline Family structure, single parent vs two parents & $1.36(0.67,2.76)$ & \\
\hline Infant gender, girl vs boy & $0.79(0.65,0.97)^{*}$ & $0.86(0.70,1.06)$ \\
\hline Parity, multipara vs primipara & $0.77(0.63,0.93)^{* *}$ & $0.85(0.68,1.08)$ \\
\hline \multicolumn{3}{|l|}{ Biological factors } \\
\hline Maternal pre-pregnancy BMI & $1.01(0.99,1.03)$ & \\
\hline Infant gestational age (weeks) & $0.90(0.82,1.00)^{*}$ & $0.94(0.84,1.04)$ \\
\hline Infant weight at birth, Z-score & $0.94(0.84,1.04)$ & \\
\hline Infant postnatal weight gain, Z-score ${ }^{a}$ & $0.92(0.80,1.06)$ & \\
\hline \multicolumn{3}{|l|}{ Behavioral factor } \\
\hline \multicolumn{3}{|l|}{ Duration of any breastfeeding } \\
\hline No breastfeeding & $2.37(1.85,3.03)^{* * *}$ & $1.91(1.44,2.52)^{* * *}$ \\
\hline Breastfeeding for $0.5-4$ months & $1.51(1.19,1.91)^{*}$ & $1.35(1.04,1.74)^{*}$ \\
\hline Breastfeeding for 4 months or longer & Ref & Ref \\
\hline \multicolumn{3}{|l|}{ Psychosocial factors } \\
\hline Maternal depressive symptoms, yes vs no ${ }^{b}$ & $1.14(0.83,1.55)$ & \\
\hline \multicolumn{3}{|l|}{ Parental perceptions on characteristics ${ }^{c}$} \\
\hline "My child drinks greedily" & $0.81(0.65,1.01)$ & \\
\hline "My child always wants to eat when he/she sees someone eating" & $1.59(1.30,1.94)^{* * *}$ & $1.44(1.16,1.79)^{* * *}$ \\
\hline "My child does not like plain water" & $1.31(1.03,1.67)^{*}$ & $1.08(0.83,1.41)$ \\
\hline "My child cried a lot in the first 3 months" & $0.93(0.72,1.20)$ & \\
\hline \multicolumn{3}{|l|}{ Parental belief about feeding ${ }^{\mathrm{C}}$} \\
\hline "Fruit and vegetables can be given to the baby freely earlier than 4 months" & $2.36(1.58,3.52)^{*}$ & $1.66(1.07,2.56)^{*}$ \\
\hline \multicolumn{3}{|l|}{ Parental beliefs about infant weight ${ }^{c}$} \\
\hline "I don't like my child to be fat" & $0.78(0.63,0.96)^{*}$ & $0.80(0.64,1.01)$ \\
\hline "I don't like my child to be thin" & $0.96(0.79,1.17)$ & \\
\hline \multicolumn{3}{|l|}{ Infant temperament } \\
\hline Soothability & $1.12(1.04,1.22)^{* * *}$ & $1.15(1.06,1.26)^{* *}$ \\
\hline Distress to limitations & $1.00(0.90,1.12)$ & \\
\hline Distress to novel food & $0.91(0.85,0.98)^{*}$ & $0.92(0.85,0.99)^{*}$ \\
\hline \multicolumn{3}{|l|}{ Social care factors } \\
\hline Day-care attendance, yes vs no & $0.63(0.51,0.78)^{* * *}$ & $0.76(0.60,0.96)^{*}$ \\
\hline "BBOFT+" intervention vs no intervention & $0.91(0.73,1.13)$ & \\
\hline
\end{tabular}

Note: Both the univariate models and the multivariate model adjusted for age at questionnaire measurement. The multivariate model included the factors significantly $(p<0.05)$ associated with the outcome variable in the univariate models

${ }^{a}$ Calculated by changes in weight for age Z-scores in the first 3 months

${ }^{\mathrm{b}}$ Maternal depression symptom was defined as scored 10 or greater on the Edinburgh Postnatal Depression Scale. This variable was defined as missing

if the questionnaire had been filled in by the father or other care givers $(n=107)$

'Agree/strongly agree vs neutral, disagree, or strongly disagree

${ }^{*} p<0.05,{ }^{* *} p<0.01,{ }^{* * *} p<0.001$, 
complementary feeding practices on infant weight gain should be aware of the reverse causality: that rapid postnatal weight gain may induce early introduction of complementary feeding.

Our study further revealed that psychosocial factors play an important role in parents' adoption of complementary feeding practices. We identified several parental perceptions/beliefs concerning infant characteristics and infant weight that may contribute to inappropriate complementary feeding practices. For instance, parents who perceived that "my child always wants to eat when he/ she sees someone eating" and parents who agree with the idea that "fruit and vegetables can be given to the child freely earlier than 4 months" were more likely to introduce complementary feeding early, and to give their infants non-recommended foods more frequently. We are aware of only one study that has included the parental perceptions or beliefs as determinants of infant complementary feeding [58], and comparison with that study is difficult because the outcome variables was defined differently. As psychosocial factors tend to be more modifiable than demographical and biological factors, in future intervention programs it would be beneficial to target these psychosocial contributors for inappropriate complementary feeding. In view of the cross-sectional nature of our data, no causal relationship can be inferred from the present study. We recommend further longitudinal studies or controlled trials to confirm our findings. In addition, we recommend conducting further qualitative or quantitative to obtain more thorough understanding of the psychosocial factors contributing to inappropriate complementary feeding.

With regard to social factors, we found that infants who attended day-care were less likely to receive complementary feeding early and were less likely to consume non-recommended foods frequently. Previous studies conducted in other countries have found no association between day-care attendance and early introduction of complementary feeding [33]. However, differences in the overall child-care systems in different countries (for example, different policies, social norms), might have influenced the findings. Consistent with our study, a previous study in the Netherlands suggested that day-care attendance is associated with less unhealthy lifestyles of young children [44]. It has also been reported that day-care attendance in the first year of life was associated with better general health and lower risk of overweight and obesity of the children across the age span of 1 to 8 years in a birth cohort from the Netherlands [59]. The association of day-care use and more favorable infant feeding practices in the present study and more favorable lifestyles and general health of children found in previous studies might reflect other characteristics of families using day-care facilities. In our study, the mothers of children who attended day-care at age 6 months were more often higher educated, employed, and less often overweight. We recommend further studies to investigate the reasons for the role of day-care attendance on children's healthy lifestyles and health outcomes.

A limitation of the present study is that the timing of introduction of complementary feeding was self-reported by parents retrospectively. However, the data were collected when infants were 6 months, which was close to the time of introduction of complementary feeding. This may have reduced the recall bias on timing of introduction of complementary feeding. Secondly, it should be noted that the participants who responded to the questionnaire had a higher educational level and higher rate of breastfeeding than those who did not. Our study may therefore have underestimated the proportion of infants in the population who had received complementary feeding before 4 months. Thirdly, it is a limitation of the present study that we were unable to precisely estimate the percentage of infants who were introduced to complementary feeding after the age of 6 months. However, this study followed the ESPHAGAN recommendation adopted by many countries in Europe, which defines early introduction of complementary feeding as the introduction of complementary feeding before 4 months $[3,5,36]$. Finally, our study used data from a cluster randomized controlled trial for prevention of childhood overweight [37]. Parents allocated to the BBOFT+ group received intervention on child-rearing practices from birth onwards. The intervention did not include specific information on timing of the introduction of complementary feeding. The intervention is unlikely to have influenced our results, as the ICC was low and a sensitivity analysis using a sample from the control group generated comparable results.

\section{Conclusions}

In conclusion, the present study addresses the need to improve the compliance with complementary feeding guidelines among parents in the Netherlands, more specifically the introduction of complementary feeding after age 4 months, and the avoidance of giving infants sweet beverages and snack foods. Factors associated with inappropriate complementary feeding practices include younger maternal age, lower maternal educational level, absence or shorter duration of breastfeeding, increased maternal pre-pregnancy BMI and infant postnatal weight gain, and not attending day-care. We also identified several psychosocial factors associated with inappropriate complementary feeding practices. These findings are relevant for designing targeted interventions aimed at educating parents to improve their complementary feeding practices. 


\section{Additional file}

Additional file 1: Table S1. Questionnaires on infant feeding used in the present study. (DOCX $25 \mathrm{~kb}$ )

\section{Abbreviations}

BMI: Body Mass Index; ESPGHAN: European Society for Pediatric Gastroenterology, Hepatology and Nutrition; ICC: Intra-class coefficient; SD: Standard Deviation; YHC: Youth Health Care

\section{Acknowledgements}

Professional advice on the English was given by J. Burrough.

\section{Funding}

The BeeBOFT study was funded by a grant from ZonMW, the Netherlands Organization for Health Research and Development (grant number 5050110-96-491). LW is supported by China Scholarship Council (CSC) PhD Fellowship for her PhD study at the Erasmus MC, Rotterdam, the Netherlands. The scholarship file number is 201506220176, CSC URL: [http:// www.csc.edu.cn/]. The funding sources had no role in study design and conduction, data collection and analysis, decision to publish, or preparation of the manuscript.

\section{Availability of data and materials}

Data are available upon reasonable request by contacting the corresponding author Hein Raat (h.raat@erasmusmc.nl).

\section{Authors' contributions}

$H R$ and $M M B$ and MLH had the original idea for the study and its design and were responsible for acquiring the study grant. AvG and EV were responsible for data collection and project coordination. LW did the data analysis, reported the results, and drafted the manuscript. AvG and HR supervised the study. All authors ( $L W, A v G, L v d V, E V, M L H, M M B, M B, H R$ ) were involved in writing the paper and approved the final manuscript.

\section{Ethics approval and consent to participate}

The research proposal was reviewed by the Medical Ethics Committee of the Erasmus University Medical Center. Based on their review, the Committee concluded that the Dutch Medical Research Involving Human Subjects Act did not apply to this research proposal. The Medical Ethics Committee therefore had no objection to the execution of this study (proposal number MEC-2008-250). Written informed consent was obtained from all the study participants.

\section{Consent for publication}

Not applicable.

\section{Competing interests}

The authors declare that they have no competing interests.

\section{Publisher's Note}

Springer Nature remains neutral with regard to jurisdictional claims in published maps and institutional affiliations.

\section{Author details}

${ }^{1}$ Department of Public Health, Erasmus University Medical Center, PO Box 2040, 3000 CA, Rotterdam, the Netherlands. ${ }^{2}$ Department of Public Health and Primary Care, Leiden University Medical Center, Den Haag, the Netherlands. ${ }^{3}$ TNO Child Health, Leiden, the Netherlands. ${ }^{4}$ Department of Agrotechnology and Food Sciences, Subdivision Human Nutrition, Wageningen University and Research, Wageningen, the Netherlands. ${ }^{5}$ Department Health Technology and Services Research, Technical Medical Center, University of Twente, Enschede, the Netherlands.
Received: 18 April 2018 Accepted: 28 March 2019

Published online: 08 April 2019

\section{References}

1. Agostoni C, Decsi T, Fewtrell M, Goulet O, Kolacek S, Koletzko B, Michaelsen KF, Moreno L, Puntis J, Rigo J. Complementary feeding: a commentary by the ESPGHAN committee on nutrition. J Pediatr Gastroenterol Nutr. 2008; 46(1):99-110.

2. Global strategy for infant and young child feeding. Geneva: World Health Organization; 2003.

3. Fewtrell M, Bronsky J, Campoy C, Domellöf M, Embleton N, Mis NF, Hojsak I, Hulst JM, Indrio F, Lapillonne A. Complementary feeding: a position paper by the European Society for Paediatric Gastroenterology, hepatology, and nutrition (ESPGHAN) committee on nutrition. J Pediatr Gastroenterol Nutr. 2017:64(1):119-32.

4. Verbrugge HP. Youth health care in the Netherlands: a bird's eye view. Pediatrics. 1990:86(6 Pt 2):1044-7.

5. Richtlijn: Voeding en eetgedrag (2013, aanpassing 2017). Guideline: Nutrition and eating behavior (2013, adaptation 2017). [https://www.ncj.nl/richtlijnen/ alle-richtlijnen/richtlijn/voeding-en-eetgedrag]. Accessed 2 Apr 2019

6. van Rossem L, Kiefte-de Jong JC, Looman CW, Jaddoe WW, Hofman A Hokken-Koelega AC, Mackenbach JP, Moll HA, Raat H. Weight change before and after the introduction of solids: results from a longitudinal birth cohort. Br J Nutr. 2013;109(2):370-5.

7. Vail B, Prentice P, Dunger DB, Hughes IA, Acerini CL, Ong KK. Age at weaning and infant growth: primary analysis and systematic review. J Pediatr. 2015;167(2):317-324 e311.

8. Baker JL, Michaelsen KF, Rasmussen KM, Sorensen TI. Maternal prepregnant body mass index, duration of breastfeeding, and timing of complementary food introduction are associated with infant weight gain. Am J Clin Nutr. 2004:80(6):1579-88

9. Huh SY, Rifas-Shiman SL, Taveras EM, Oken E, Gillman MW. Timing of solid food introduction and risk of obesity in preschool-aged children. Pediatrics. 2011;127(3):e544-51.

10. Pearce J, Taylor MA, Langley-Evans SC. Timing of the introduction of complementary feeding and risk of childhood obesity: a systematic review. Int J Obes. 2013:37(10):1295-306.

11. Moss BG, Yeaton WH. Early childhood healthy and obese weight status: potentially protective benefits of breastfeeding and delaying solid foods. Matern Child Health J. 2014;18(5):1224-32.

12. Daniels $L$, Mallan KM, Fildes A, Wilson J. The timing of solid introduction in an 'obesogenic' environment: a narrative review of the evidence and methodological issues. Aust N Z J Public Health. 2015;39(4):366-73.

13. Carletti C, Pani P, Monasta L, Knowles A, Cattaneo A. Introduction of complementary foods in a cohort of infants in Northeast Italy: do parents comply with WHO recommendations? Nutrients. 2017:9:1.

14. McAndrew F, Thompson J, Fellows L, Large A, Speed M, Renfrew MJ. Infant feeding survey 2010. Leeds: Health and Social Care Information Centre; 2012.

15. Clayton HB, Li R, Perrine CG, Scanlon KS. Prevalence and reasons for introducing infants early to solid foods: variations by milk feeding type. Pediatrics. 2013;131(4):e1108-14.

16. (USDA) USDoA. Infant nutrition and feeding: a guide for use in the WIC and CSF programs. Washington, DC: USDA; 2008

17. Rose CM, Birch LL, Savage JS. Dietary patterns in infancy are associated with child diet and weight outcomes at 6 years. Int J Obes. 2017;1:6.

18. Park S, Pan L, Sherry B, Li R. The association of sugar-sweetened beverage intake during infancy with sugar-sweetened beverage intake at 6 years of age. Pediatrics. 2014;134(Supplement 1):S56-62.

19. Hoekstra JH. Toddler diarrhoea: more a nutritional disorder than a disease. Arch Dis Child. 1998:79(1):2-5.

20. Smith MM, Lifshitz F. Excess fruit juice consumption as a contributing factor in nonorganic failure to thrive. Pediatrics. 1994;93(3):438-43.

21. Holt RD, Moynihan PJ. The weaning diet and dental health. Br Dent J. 1996 ; 181(7):254-9.

22. Fox MK, Pac S, Devaney B, Jankowski L. Feeding infants and toddlers study: what foods are infants and toddlers eating? J Am Diet Assoc. 2004;104(1 Suppl 1):s22-30.

23. Tarrant RC, Younger KM, Sheridan-Pereira M, White MJ, Kearney JM. Factors associated with weaning practices in term infants: a prospective observational study in Ireland. Br J Nutr. 2010;104(10):1544-54. 
24. Hendricks K, Briefel R, Novak T, Ziegler P. Maternal and child characteristics associated with infant and toddler feeding practices. J Am Diet Assoc. 2006; 106(1 Suppl 1):S135-48.

25. Schrempft S, van Jaarsveld $\mathrm{CH}$, Fisher A, Wardle J. Family and infant characteristics associated with timing of core and non-core food introduction in early childhood. Eur J Clin Nutr. 2013;67(6):652-7.

26. Kronborg H, Foverskov E, Vaeth M. Predictors for early introduction of solid food among Danish mothers and infants: an observational study. BMC Pediatr. 2014;14:243.

27. Scott JA, Binns CW, Graham Kl, Oddy WH. Predictors of the early introduction of solid foods in infants: results of a cohort study. BMC Pediatr. 2009;9:60.

28. Klingberg S, Ludvigsson J, Brekke HK. Introduction of complementary foods in Sweden and impact of maternal education on feeding practices. Public Health Nutr. 2016:1-9.

29. Tromp II, Briede S, Kiefte-de Jong JC, Renders CM, Jaddoe WW, Franco OH, Hofman A, Raat H, Moll HA. Factors associated with the timing of introduction of complementary feeding: the generation R study. Eur J Clin Nutr. 2013;67(6):625-30.

30. Tatone-Tokuda F, Dubois L, Girard M. Psychosocial determinants of the early introduction of complementary foods. Health Educ Behav. 2009:36(2):302-20.

31. Castro PD, Kearney J, Layte R. A study of early complementary feeding determinants in the Republic of Ireland based on a cross-sectional analysis of the growing up in Ireland infant cohort. Public Health Nutr. 2015;18(2): 292-302.

32. Doub AE, Moding KJ, Stifter CA. Infant and maternal predictors of early life feeding decisions. The timing of solid food introduction. Appetite. 2015;92: 261-8.

33. Wijndaele K, Lakshman R, Landsbaugh JR, Ong KK, Ogilvie D. Determinants of early weaning and use of unmodified cow's milk in infants: a systematic review. J Am Diet Assoc. 2009;109(12):2017-28.

34. Wasser H, Bentley M, Borja J, Davis Goldman B, Thompson A, Slining M, Adair L. Infants perceived as "fussy" are more likely to receive complementary foods before 4 months. Pediatrics. 2011;127(2):229-37.

35. Brown A, Rowan H. Maternal and infant factors associated with reasons for introducing solid foods. Matern Child Nutr. 2016;12(3):500-15.

36. Schiess S, Grote V, Scaglioni S, Luque V, Martin F, Stolarczyk A, Vecchi F, Koletzko B. European childhood obesity P: Introduction of complementary feeding in 5 European countries. J Pediatr Gastroenterol Nutr. 2010;50(1):92-8.

37. Raat H, Struijk MK, Remmers T, Vlasblom E, van Grieken A, Broeren SML, te Velde SJ, Beltman M, Boere-Boonekamp MM, L'Hoir MP. Primary prevention of overweight in preschool children, the BeeBOFT study (breastfeeding, breakfast daily, outside playing, few sweet drinks, less TV viewing): design of a cluster randomized controlled trial. BMC Public Health. 2013;13:974.

38. Alzaheb RA. Factors associated with the early introduction of complementary feeding in Saudi Arabia. Int J Environ Res Public Health. 2016;13(7).

39. Netherlands S. Dutch standard classification of education 2003. Voorburg/ Heerlen: Statistics Netherlands; 2004.

40. How does Statistics Netherlands define an immigrant [https:/www.cbs.n//nl-nl/ faq/specifiek/wat-verstaat-het-cbs-onder-een-allochtoon-]. Accessed 2 Apr 2019.

41. Signaleringsprotocol overgewicht in de jeugdsgezondheidszorg Youth health care overweight-detection-protocol [https://www.ggdghorkennisnet. $\mathrm{nl} /$ ?file $=748 \& \mathrm{~m}=1310480599 \&$ action=file.download]. Accessed 2 Apr 2019.

42. Fredriks AM, Van Buuren S, Burgmeijer RJF, Meulmeester JF, Beuker RJ, Brugman E, Roede MJ, Verloove-Vanhorick SP, Wit J-M. Continuing positive secular growth change in the Netherlands 1955-1997. Pediatr Res. 2000; 47(3):316-23.

43. Cox JL, Holden JM, Sagovsky R. Detection of postnatal depression. Development of the 10-item Edinburgh postnatal depression scale. $\mathrm{Br} \mathrm{J}$ Psychiatry. 1987;150(6):782-6.

44. Boere-Boonekamp MM, L'Hoir MP, Beltman M, Bruil J, Dijkstra N, Engelberts AC. Overweight and obesity in preschool children (0-4 years): behaviour and views of parents. Ned Tijdschr Geneeskd. 2008;152(6):324-30.

45. Rothbart MK. Measurement of temperament in infancy. Child Dev. 1981:569-78.

46. Boudet-Berquier J, Salanave B, de Launay C, Castetbon K. Introduction of complementary foods with respect to French guidelines: description and associated socio-economic factors in a nationwide birth cohort (Epifane survey). Matern Child Nutr. 2016.

47. Rasmussen KM, Kjolhede CL. Prepregnant overweight and obesity diminish the prolactin response to suckling in the first week postpartum. Pediatrics. 2004;113(5):e465-71.
48. Buonfiglio DC, Ramos-Lobo AM, Freitas VM, Zampieri TT, Nagaishi VS, Magalhaes M, Cipolla-Neto J, Cella N, Donato J Jr. Obesity impairs lactation performance in mice by inducing prolactin resistance. Sci Rep. 2016;6:22421.

49. Garcia AH, Voortman T, Baena CP, Chowdhurry R, Muka T, Jaspers L, Warnakula S, Tielemans MJ, Troup J, Bramer WM, et al. Maternal weight status, diet, and supplement use as determinants of breastfeeding and complementary feeding: a systematic review and meta-analysis. Nutr Rev. 2016;74(8):490-516.

50. Jobe AH. Age of weaning and infant growth. J Pediatr. 2015;167(2):219-21.

51. Wright CM, Parkinson KN, Drewett RF. Why are babies weaned early? Data from a prospective population based cohort study. Arch Dis Child. 2004; 89(9):813-6

52. Baird J, Fisher D, Lucas P, Kleijnen J, Roberts H, Law C. Being big or growing fast: systematic review of size and growth in infancy and later obesity. Bmj. 2005:331(7522):929.

53. Monteiro PO, Victora CG. Rapid growth in infancy and childhood and obesity in later life--a systematic review. Obes Rev. 2005;6(2):143-54.

54. Salgin B, Norris SA, Prentice P, Pettifor JM, Richter LM, Ong KK, Dunger DB. Even transient rapid infancy weight gain is associated with higher BMI in young adults and earlier menarche. Int J Obes. 2015;39(6):939-44.

55. Singhal A, Cole TJ, Fewtrell M, Deanfield J, Lucas A. Is slower early growth beneficial for long-term cardiovascular health? Circulation. 2004;109(9):1108-13.

56. Leunissen RW, Kerkhof GF, Stijnen T, Hokken-Koelega A. Timing and tempo of first-year rapid growth in relation to cardiovascular and metabolic risk profile in early adulthood. Jama. 2009;301(21):2234-42.

57. Marinkovic T, Toemen L, Kruithof CJ, Reiss I, van Osch-Gevers L, Hofman A Franco $\mathrm{OH}$, Jaddoe WW. Early infant growth velocity patterns and cardiovascular and metabolic outcomes in childhood. J Pediatr. 2017:186: 57-63 e54.

58. Thompson AL, Bentley ME. The critical period of infant feeding for the development of early disparities in obesity. Soc Sci Med. 2013;97:288-96.

59. Ruijsbroek A, Wijga AH, Kerkhof M, Koppelman GH, Smit HA, Droomers M. The development of socio-economic health differences in childhood: results of the Dutch longitudinal PIAMA birth cohort. BMC Public Health. 2011; 11(1):225

Ready to submit your research? Choose BMC and benefit from:

- fast, convenient online submission

- thorough peer review by experienced researchers in your field

- rapid publication on acceptance

- support for research data, including large and complex data types

- gold Open Access which fosters wider collaboration and increased citations

- maximum visibility for your research: over $100 \mathrm{M}$ website views per year

At BMC, research is always in progress.

Learn more biomedcentral.com/submissions 